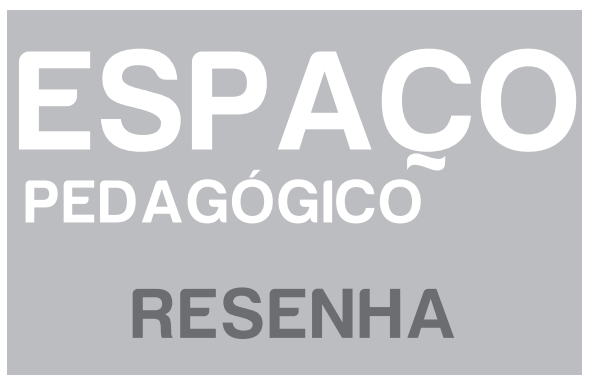





\section{M-learning e u-learning: novas perspectivas das aprendizagens móvel e ubíqua' ${ }^{1}$}

Patrícia Grasel*

A obra é resultado dos estudos sobre tecnologia móvel realizados pelos três autores: o professor e pesquisador na área das tecnologias móveis Jorge Luis Victória Barbosa, a doutora e pesquisadora em Administração Amarolinda Zanela Saccol e a também doutora em Informática na Educação Eliane Schlemmer, todos docentes na Universidade do Vale do Rio dos Sinos (Unisinos/RS).

Como traduzido no próprio título da obra, os autores tratam de conceitos fundamentais relacionados às possibilidades que as Tecnologias da Informação e Comunicação (TICs) móveis e sem fio podem significar para os processos de ensino e aprendizagem. O conteúdo do livro traz importantes contribuições para o leitor compreender melhor o que são as novas modalidades de educação, quais as principais tecnologias que as apoiam, quais metodologias e processos de mediação pedagógica relacionam-se a ela, além de compartilhar práticas e experiências.

Durante a leitura, emergem questões relevantes em torno dos conceitos de $m$ -learning e u-learning, reunindo conhecimento formal referente às práticas de uso das tecnologias móvel e sem fio. O olhar dos autores é oriundo de distintas áreas, como educação, gestão e computação.

O livro é organizado em quatro capítulos, no primeiro dos quais se oferece uma visão geral dos conceitos envolvidos nas tecnologias da informação e comunicação; no segundo, apresentam-se, detalhadamente, os conceitos de m-learning e u-learning; no terceiro, discutem-se e analisam-se práticas pedagógicas envolvendo m-learning e u-learning; e, por fim, no quarto capítulo, expõem-se ferramentas para m-learning e u-learning.

Recebido: 26/04/2013 - Aprovado: 08/06/2013

http://dx.doi.org/10.5335/rep.2013.3564

Doutoranda do Programa de Informática na Educação da Universidade Federal do Rio Grande do Sul (PGIE/UFRGS) e Mestra em Educação pela mesma Universidade. Pedagoga, especialista em Multimeios e Informática Educativa pela Pontifícia Universidade Católica do Rio Grande do Sul (PUCRS). Professora na graduação da Universidade do Vale do Rio dos Sinos, nos cursos de licenciaturas e Assessora Pedagógica na área de Educação a Distância. E-mail: patrícia.grasel@gmail.com. 
Como se afirmou, na parte inicial da obra são apresentados os conceitos que servem como base para as discussões, tais como: o que é informação, o que é aprendizagem, o que é conhecimento e como as tecnologias móveis e sem fio podem colaborar na aprendizagem.

Os autores embasam suas reflexões sobre os avanços tecnológicos em Castells (1999), que disserta sobre sociedade em rede, apontando-a como um cenário cada vez mais rico em tecnologias. Tais tecnologias mudam, alteram, interferem na maneira que vivemos, convidando, principalmente, a educação a novos desafios para os processos de aprendizagens. Segundo os autores, essas alterações tecnológicas interferem não apenas na educação, mas também na formação do cidadão para 0 convívio em sociedade, para o mundo do trabalho e para o aprendizado contínuo, tendo em vista que as práticas sociais, as relações de trabalho e as necessidades de formação e capacitação profissional também se modificam rapidamente.

No contexto da informática educativa, esse cenário de mudanças tem influenciado as práticas docentes, pois as ações metodológicas que as tecnologias móveis acionam vão além dos espaços físicos, uma vez que os recursos são móveis e as possibilidades, ubíquas. No entanto, percebe-se, no conteúdo do livro, que não basta 0 acesso às tecnologias digitais; também, é preciso saber utilizá-las para o desenvolvimento de aprendizagens significativas junto aos sujeitos.

Os autores apresentam o conceito de informação, afirmando que esta não é o mesmo que conhecimento, que, por sua vez, também é diferente de aprendizagem. Ao interagir com alguma mídia impressa ou digital, já estamos em contato com a informação, pois o conteúdo compartilhado nesses meios de comunicação é informação. Quando conversamos, contamos um fato e/ou caso estamos compartilhando informação, que é transmitida, utilizada, manipulada e compartilhada.

Quanto ao conceito de aprendizagem, os autores realizam sua fundamentação apoiados, especialmente, em Jean Piaget e Humberto Maturana. Para Piaget, a aprendizagem é, em geral, provocada por situações externas ao sujeito e só acontece quando há assimilação ativa por parte deste. A ênfase é colocada na atividade do próprio sujeito, ou seja, a importância da sua ação frente à atividade é o que o responsabiliza pelo seu próprio processo de aprender. O sujeito precisa agir sobre o objeto de conhecimento e compreendê-lo. Segundo Humberto Maturana, a aprendizagem é um ato de transformar-se em um meio particular de interações recorrentes.

Ainda com base nas teorias de Piaget e Maturana, os autores da obra aqui resenhada afirmam que a aprendizagem ocorre quando a conduta de um organismo varia durante sua ontogenia, ou seja, ocorre aprendizagem quando um sujeito se modifica a partir da sua história de interações com o meio. O sujeito produz a si 
mesmo, através da história de interações no meio em que está inserido (autopoiese).

Outro conceito-chave apresentado na obra é o de conhecimento, entendido não como simples reprodução da realidade. Conhecer é interagir com o objeto, compreender o seu processo de transformação, compreender como é construído e identificar seus resultados. O conhecimento é pessoal, depende do sujeito, pois é construído por ele. Maturana e Varela (2001) afirmam que o conhecimento é algo que o ser vivo constrói nas suas interações com o mundo. Nesse sentido, todo conhecer é parte da ação daquele que conhece. O conhecimento diferencia-se da informação por estar relacionado a uma intencionalidade de quem deseja conhecer.

Os autores embasam o leitor com conceitos de informação, conhecimento e aprendizagem para, em seguida, abordá-los nos processos de aprendizagem viabilizados pelas TICs móveis e sem fio.

O terceiro capítulo discute e analisa práticas pedagógicas envolvendo m-learning e u-learning. De acordo com os autores, a construção do conhecimento através do m-learning não precisa ficar limitada a um espaço fixo ou formal de aprendizagem. O uso de tecnologia móvel valoriza a instantaneidade na comunicação, considerando que o tempo é um recurso cada vez mais escasso, cujo valor econômico precisa ser otimizado por meio da ocupação minuciosa até dos menores intervalos. Sendo assim, trabalhar no planejamento de objetos multimodais para contribuir com a otimização e a qualidade do tempo é uma poderosa alternativa para diferentes espaços na sociedade em rede.

O conceito de m-learning é apresentado pelos autores como mais uma comprovação de que as tecnologias digitais disponíveis renovam-se a cada mês. Um exemplo é o próprio conceito de web. Há pouco tempo, falava-se da web 1.0, que permitia ao usuário explorar informações disponibilizadas na rede. Nesse contexto, o sujeito é um usuário espectador. A web 2.0 possibilita que os exploradores passem da posição de consumidores de informações para colaboradores e construtores de informações. E a web 3.0 tem em vista os exploradores imersos nas redes sociais através de agentes inteligentes.

No capítulo final, são apresentadas ao leitor as principais tecnologias móveis e sem fio, que apoiam os conceitos de m-learning e u-learning, integrando computação, comunicação e dispositivos com sensores incorporados à vida diária, a fim de possibilitar que a aprendizagem torne-se ainda mais imersiva.

É possível encontrar na leitura declarações feitas pelos autores com base em Kadirire (2009) sobre a notável popularização de dispositivos móveis como telefones celulares, notebooks, palmtops, smartphones, dentre outros. Essas tecnologias móveis cresceram rapidamente, os primeiros sistemas de telefonia móvel, 
por exemplo, começaram a ser difundidos para a população em geral no início da década de 1980.

O olhar dos autores na obra é dirigido para os recursos digitais, o que pode ser observado durante a leitura, principalmente a partir do terceiro capítulo. Muitas situações contribuem para a imersão ao meio digital, segundo os autores, pois a internet, com sua presença garantida em diferentes contextos e lugares, tornou-se um passaporte de entrada para as pessoas vivenciarem diferentes situações em seu cotidiano, mesmo para aquelas que fazem uso dessa rede apenas profissionalmente.

Entre as experiências compartilhadas no livro, é possível identificar que existe um grupo considerável de jovens e adultos que utilizam os recursos digitais para qualificar suas ações diárias. Esses recursos digitais geralmente favorecem uma comunicação rápida, instantânea, com diferentes pessoas que estão em variados espaços e lugares, o que contribui para o trânsito ativo e plural no ciberespaço.

Viver e conviver em um mundo cada vez mais cheio de recursos digitais tecnológicos, em uma sociedade em rede, de acordo com Castells (1999), traz consequências importantes, representando significativos desafios para os processos de ensino e aprendizagem, tanto no contexto formal como no contexto não formal. Para os autores, essa nova realidade influencia não só a maneira de se trabalhar em educação, como também a maneira de preparar o indivíduo para sociedade, para o mundo do trabalho e para o aprendizado contínuo, uma vez que as práticas sociais, as relações de trabalho e as necessidades de formação e capacitação profissional também se modificam rapidamente.

De acordo com o conceito de aprendizagem que os autores adotam para embasar suas discussões, a ênfase é colocada na atividade do sujeito, de modo que sua ação na aprendizagem atribui-lhe a responsabilidade pelo seu processo de aprender. Aprendizagem é o ato de transformar-se, em um meio particular de interações recorrentes. Conforme o embasamento teórico adotado pelos autores da obra que se está resenhando, a aprendizagem ocorre quando a conduta de um organismo varia durante sua ontogenia (é a história do ser vivo desde o seu nascimento até sua morte) de maneira congruente com as variações do meio, o que faz seguindo um curso contingente nas suas interações com ele. De forma simplificada, significa dizer que ocorre aprendizagem quando um ser vivo se modifica a partir da sua história de interações com o meio. Aprender utilizando tecnologias móveis é aprender em processos de mobilidade e ubiquidade, o que implica abrir-se às potencialidades que esses objetos oferecem, envolve aguçar o senso de observação do entorno para perceber tais possibilidades, ser autônomo e autor do seu processo de aprender. 
Essa preocupação em fazer o leitor compreender o processo de aprendizagem é, justamente, o que embasa as discussões sobre as novas possibilidades metodológicas do uso de $m$-learning e $u$-learning. Não seria adequado refletir sobre o uso dos recursos digitais móveis na educação sem compreender a real importância que se faz na intenção pedagógica, nos sentidos e nas finalidades do uso, nas contribuições que emergem do uso, dentre outros.

De acordo com os autores, as características da m-learning abrem um leque de possibilidades no âmbito da formação para o emprego, visto que, no mundo do trabalho, a formação requer um caráter muito mais prático. $\mathrm{O}$ ideal é que a capacitação se produza onde e quando se necessite, que se libere o aluno da necessidade de estar num espaço limitado, em frente a um computador.

Para o desenvolvimento de conteúdos destinados a m-learning, os autores propõem que estes devem contemplar desenho simples, menor densidade de informação, conteúdo multimídia, caráter colaborativo e aplicações específicas. Dessa forma, deve-se atender às seguintes características: módulos curtos e diretos (5 minutos); material multimídia; focados no presente: "aqui e agora"; material continuamente atualizado; adaptado ao tamanho da tela.

Em síntese, no livro, discute-se sobre conceitos de tecnologias móveis como recursos educacionais, com base em aspectos pedagógicos a serem considerados, como os processos de aprendizagem. Deixa-se claro que não bastam os recursos sem metodologias de uso, mas que as metodologias precisam ser repensadas a partir dos novos recursos, que, por sua vez, provocam diferentes estilos de aprendizagens. Os conceitos de m-learning e $u$-learning são apresentados como novas perspectivas da aprendizagem móvel e ubíqua, como ferramenta essencial para professores e gestores das mais diversas áreas e instituições de ensino, bem como para profissionais ligados à educação corporativa. A sociedade em rede oferece os recursos. Agora, o desafio é saber utilizá-los com intenções pedagógicas significativas.

\section{Nota}

1 Resenha da obra: SACCOL, Amarolinda; SCHLEMMER, Eliane; BARBOSA, Jorge. M-learning e u-learning: novas perspectivas das aprendizagens móvel e ubíqua. São Paulo: Pearson Prentice Hall, 2011. 


\section{Referências}

CASTELLS, M. A sociedade em rede. São Paulo: Paz e Terra, 1999.

KADIRIRE, J. Mobile learning demystified. In: GUY, R. The evolution of mobile teaching and learning. Santa Rosa: Informing Science Press, 2009. v. 1. p. 103-118.

MATURANA, H. Uma nova concepção de aprendizagem. Dois Pontos, v. 2, n. 15, p. 28-35, 1993. . Transformación em la convivência. Chile: Dolmen Ediciones, 1999. . A ontologia da realidade. Belo Horizonte: Ed. da UFMG, 2001.

A árvore do conhecimento: as bases biológicas do entendimento humano. São Paulo: Pallas Athena, 2001.

PIAGET, J. Development and learning. In: LAVATELLY, C.; STENDLER, F. Reading in child behavior and development. Nova York: Hartcourt Brace Janovich, 1972.

. Estudos sociológicos. Rio de Janeiro: Companhia Editora Forense, 1973.

. Abstração reflexionante: relações lógico-aritméticas e ordem das relações espaciais. Porto Alegre: Artes Médicas, 1995. 